
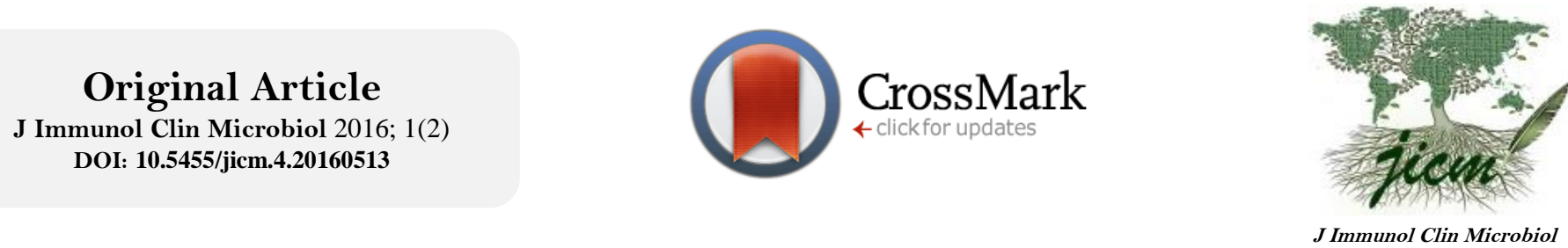

\title{
Antibiotic susceptibilities of bacteria isolated from chronic suppurative otitis media
}

\author{
Arif Hikmet CATAKOGLU ${ }^{1 *}$, Ridvan GUCKAN ${ }^{2}$, Cetin KILINC ${ }^{2}$, Mehmet Mustafa ERDOGAN ${ }^{1}$, \\ Dursun Murat ALADA ${ }^{3}$, Keramettin YANIK ${ }^{4}$ \\ 1 Amasya University, Sabuncuoglu Serafettin Education and Research Hospital, Department of Otorhinolaryngology, Amasya, \\ Turkey. 2 Amasya University, Sabuncuoglu Serafettin Education and Research Hospital, Department of Medical Microbiology \\ Amasya, Turkey. 3 Ağrı State Hospital, Ağrı, Turkey. 4 Ondokuz Mayis University Medical Faculty Hospital, Department of \\ Medical Microbiology, Samsun, Turkey.
}

\begin{abstract}
Background: To identify the bacteria that cause chronic suppurative otitis media and determine their antibiotic susceptibilities.

Material and Methods: We examined bacterial cultures that were isolated from the ear discharge of 180 patients who were admitted to the otolaryngology clinic between September 2014 and October 2015 due to suppurative bluishgreen discharge from the middle ear. We also assessed the antibiotic susceptibilities of these microorganisms by retrospectively using the results of particular tests. The identification and antibiograms of bacteria were carried out using the VITEK 2 automated system.

Results: Microbial growth was detected in 162 of 180 samples (90\%). The most frequently isolated strains were P. aeruginosa in 58 samples (35.8\%) and S. aureus in 34 samples (20.9\%). P. aeruginosa strains showed the highest sensitivity to amikacin (3.4\%) and gentamicin (3.4\%), but showed the greatest resistance to cefuroxime (82.7\%) and trimethoprim/sulfamethoxazole (89.6\%). S. aureus showed the lowest resistance to vancomycin (\%0) and highest resistance to penicillin (88.2\%) respectively.

Conclusion: We detected low resistance to aminoglycosides and quinolones, which are frequently used in the treatment of chronic suppurative otitis media. The detection of microorganisms, and a prior knowledge of their antibiotic susceptibilities, will contribute to successfully treating this disease.
\end{abstract}

Key words: Otitis media, Pseudomonas aeruginosa, Staphylococcus aureus

*Corresponding Author: Arif Hikmet ÇATAKOGLU; Amasya University, Sabuncuoglu Serafettin Education and Research Hospital, Dept. of Otorhinolaryngology, Amasya, Turkey. E-mail: drarifhikmet@hotmail.com

Received: Apr 08, 2016 Accepted: May 13, 2016 Published

Online: May 18, 2016

This is an Open Access article distributed under the terms of the Creative Commons Attribution Non-Commercial License (http://creativecommons.org/licenses/bync/4.0/) which permits unrestricted non-commercial use, distribution, and reproduction in any medium, provided

\section{Introduction}

Chronic suppurative otitis media (CSOM) is a disease that is characterized by eardrum perforation and suppurative discharge, and thus chronic inflammation in the middle ear, mastoid cavities, and infection. Acute infections improve within six weeks, but irreversible alterations begin when the infection and suppuration continue for longer than six weeks. If the active suppuration continues for longer than three months, and if there is an absence of response to medical treatment, the disease is accepted as being chronic $(1,2)$. CSOM 
can be treated in a number of ways, and it sometimes requires the long-term use of antibiotics (3).

The aim of acute otitis media (AOM) and CSOM treatment is to obtain a dry ear that does not contain necrotic tissue and inflammation. Therefore, it is important to possess knowledge of the pathogens involved, as well as their antibiotic susceptibilities, in order to successfully treat this disease.

In this study, we aimed to identify the bacteria involved and determine their antibiotic susceptibilities in order to improve the treatment of CSOM.

\section{Materials and methods}

We examined bacterial cultures that were isolated from the suppurative bluish-green discharge of 180 CSOM patients who visited the otolaryngology clinic in Amasya University, Şerefeddin Sabuncuoğlu Training and Research Hospital, Turkey between September 2015 and October 2015. The patients complained of middle ear discharge, and samples of this discharge were collected from patients who had not received any specific medication in the previous 30 days. Cultures were collected according to standard procedures using sterile swabs, and all samples were transferred to the laboratory without informing the laboratory staff of their nature. In order to culture the anaerobic bacteria, we seeded samples in 5\% sheep blood agar, eozin metilen blue agar, and chocolate agar, and microbial growth was evaluated 24 and 48 hours after incubation. Colony morphologies and Gram staining features of microorganisms were identified using conventional techniques. In addition, the antibiotic susceptibilities of these bacteria were determined using VITEK 2 (bioMerieux, France) automated systems, and were retrospectively evaluated. We did not include patients who had used antibiotics in the previous one month, those who had been hospitalized for any reason, and those who had immune deficiency or cleft palate abnormalities.

\section{Results}

Microbial growth was detected in 162 of the 180 samples (90\%). A mixed growth of bacteria and fungus was observed in nine patients. We observed no growth in 18 samples. The isolated strains were found in the following order of frequency: Pseudomonas aeruginosa in 58 patients (35.8\%), Staphylococcus aureus in 34 patients (20.9\%) and Coagulase-negative staphylococci (CNS) in 20 patients $(12.3 \%)$. The list of isolated bacteria is summarized in Table in Table 1.

$P$. aeruginosa strains were most frequently isolated, and amikacin (3.4\%) and gentamycin (3.4\%) were the most effective antibiotics for these strains (bacteria showed the least resistance to these antibiotics). Other antibiotics that were also effective against $P$. aeruginosa strains were imipenem (5.1\%), ceftazidime (6.8\%), ciprofloxacin (13.7\%), and piperacillin/tazobactam (24.1\%. The highest resistance rates were observed for cefuroxime $(82.7 \%)$ and trimethoprim/sulfamethoxazole (89.6\%) antibiotics (Table 2).

Table 1. The distribution of pathogens isolated from patients with otitis media.

\begin{tabular}{lll}
\hline Isolated bacteria & $\mathrm{n}$ & $\%$ \\
\hline P. aeruginosa & 58 & 35.8 \\
S. aureus & 34 & 20.9 \\
CNS & 20 & 12.3 \\
Proteus spp. & 12 & 7.4 \\
E. coli & 10 & 6.1 \\
K. pneumoniae & 7 & 4.3 \\
Enterobacter spp. & 6 & 3.7 \\
S. pneumonia & 6 & 3.7 \\
Other bacteria* & 9 & 5.8 \\
Total & 162 & 100 \\
\hline
\end{tabular}

CNS: Coagulase-negative staphylococci, *Acinetobacter spp., Citrobacter spp., Enterococcus spp., Morganella spp.

Table 2. Antibiotic resistance profile of isolated $P$. aeruginosa strains.

\begin{tabular}{lll}
\hline Antibiotics & n & \% \\
\hline Amikacin & $2 / 58$ & 3.4 \\
Gentamicin & $2 / 58$ & 3.4 \\
Imipenem & $3 / 58$ & 5.1 \\
Ceftazidime & $4 / 58$ & 6.8 \\
Ciprofloxacin & $8 / 58$ & 13.7 \\
Piperacillin/Tazobactam & $14 / 58$ & 24.1 \\
Cefuroxime & $48 / 58$ & 82.7 \\
Trimethoprim/Sulfamethoxazole & $52 / 58$ & 89.6 \\
\hline
\end{tabular}

$S$. aureus strains were the second most frequently isolated pathogens from our samples, and we determined that these strains showed the least resistance to vancomycin and trimethoprim/sulfamethoxazole, but showed the most resistance to penicillin (88.2\%) (Table $3)$. 
Table 3. Antibiotic resistance profile (\%) of isolated $S$. aureus strains.

\begin{tabular}{llr}
\hline Antibiotics & n & \% \\
\hline Penicillin & $30 / 34$ & 88,2 \\
Erythromycin & $6 / 34$ & 17,6 \\
Clindamycin & $6 / 34$ & 17,6 \\
Gentamicin & $4 / 34$ & 11,7 \\
Ciprofloxacin & $4 / 34$ & 11.7 \\
Cefuroxime & $3 / 34$ & 8,8 \\
Oxacillin & $3 / 34$ & 8.8 \\
Trimethoprim/Sulfamethoxazole & $2 / 34$ & 5.8 \\
Vancomycin & $0 / 34$ & 0 \\
\hline
\end{tabular}

\section{Discussion}

CSOM is commonly observed throughout the world and is one of the most frequently occurring infections. Ear discharge and hearing loss is found in the majority of patients, whereas some may be asymptomatic $(1,4)$. CSOM can lead to a variety of extracranial (bone destruction mastoiditis and petrozit, subperiosteal abscess, facial paralysis, and labyrinthitis) and intracranial (meningioma, extradural abscess, subdural abscess, brain abscess, lateral sinus thrombophlebitis, and otitis media hydrocephalus) complications. Medical treatment is the first and most important option in the treatment of CSOM, and its basis is the detection of the microorganisms involved and the administration of appropriate antibiotic(s) in adequate doses and duration $(5,6)$. Pathogens that lead to CSOM and AOM are highly variable; it is primarily $P$. aeruginosa and $S$. aureus that cause CSOM, while AOM most frequently occurs as a result of Sreptococcus pneumonia, Haemophilus influenza, and Moraxella catarrhalis infection (7).

In our study, we detected $P$. aeruginosa (35.8\%), $S$. aureus (20.9\%), and CNS (12.3\%) as disease factors, and the order of frequency in which they were found is in accordance with the results of other studies: Ozbakkaloglu et al (8) identified $P$.aeruginosa (32\%) and $S$. aureus (26\%) as the most common causative factors in 309 CSOM patients, Gorur et al.(9) showed that $P$. aeruginosa (51.2\%) and Proteus spp. (13\%) were the most common, and Gul et al.(10) found that $P$. aeruginosa $(23 \%)$ and $S$. aureus $(18 \%)$ were the most frequently observed causative factors. International studies performed by Sharma et al. (11) and Kumar et al. (12) showed that CSOM primarily occurred as a result of $P$. aeruginosa (47.2\% and $42.2 \%$, respectively) and $S$. aureus (27\% and $34.4 \%$, respectively) infections.
P. aeruginosa bacteria are associated with high mortality, morbidity, and a capacity to spread very rapidly. They are primarily observed in older people, in those with diabetes, and in individuals whose immune system is repressed $(13,14)$. P. aeruginosa rarely affects the epithelium of healthy individuals other than via the external auditory meatus (15).

Regarding the antibiotic susceptibilities of $P$. aeruginosa strains in CSOM patients, Gul et al. (10) found that $P$. aeruginosa strains were susceptible to ceftazidime and imipenem (100\%), ciprofloxacin (92\%), and gentamicin and amikacin (85\%). On the other hand, Sanl1 et al. (16) showed that $P$. aeruginosa strains were susceptible to piperacillin/tazobactam and ceftazidime (100\%). Additional to national studies, Malkappa et al. (17) found that the maximum susceptibility was observed for amikacin and Sharma et al. (11) found that the maximum susceptibility was observed for imipenem and tobramycin. In our study, we found that amikacin and gentamycin antibiotics were more effective in $P$. aeruginosa strains compared to other antibiotics. Imipenem was the second most effective antibiotic, and strains showed the highest resistance to cefuroxime and trimethoprim/sulfamethoxazole.

$S$. aureus strains are those that are most commonly isolated from CSOM patients, and the highest susceptibilities were observed for vancomycin and ciprofloxacin by Gul et al. (11), and for ampicillinsulbactam antibiotics by Gorur et al. (10). According to our findings, the most effective antibiotic was vancomycin for $S$. aureus strains, while the susceptibility was $88.3 \%$ for gentamicin and ciprofloxacin, which have important roles in COM treatment.

$S$. pneumoniae strains are rarely observed in CSOM cases. Similarly, we excluded $S$. pneumoniae strains at $3.7 \%$. In addition, we did not detect $H$. influenzae strains in any of our cases. This was because the Haemophilus species rarely causes CSOM, and also we did not use the appropriate medium in our study.

\section{Conclusion}

We detected low levels of resistance to aminoglycosides and quinolones, although these antibiotics have long been used to treat ear infections. High levels of $P$. aeruginosa and $S$. aureus isolation from CSOM patients can be associated with the easy settlement of these strains in atrophied and weak tissues. Therefore, the 
identification of disease factors in CSOM patients and selection of the most suitable antibiotics will lead to rapid and effective treatments. In addition, it will also be possible to prevent potential complications.

\section{Acknowledgements}

The authors did not receive any financial support from any public or private sources. The authors have no financial or proprietary interest in a product, method, or material described herein.

Contributions: The authors contributed equally.

Ethical standards: The experiments comply with the current laws of the Republic of Turkey.

\section{Informed Consent: N.A.}

Peer-review: Externally peer-reviewed.

Conflict of Interest: No conflict of interest was declared by the author.

Financial Disclosure: The author declared that this study has received no financial support.

\section{References}

1. Celik O. Otolaryngology and Head and Neck Surgery. Turgut publishing, İstanbul 2002.p.160- 192.

2. Goycoolec MV, HvebMM, Ruchc. Otitis media, the pathogenesis approach. Otolaryngol clin North Am 1991; 24: 757- 761.

3. Fishman AJ, Marrinan MS, Huang TC, Kanowitz SJ. Total tympanic membrane reconstruction: AlloDerm versus temporalis fascia. Otolaryngol Head Neck Surg 2005; 132: 906-915.

4. Mayerhoff WL. Pathology of chronic suppurative otitis media. Ann Otol Rhinol Laryngol 1988; 97: 21-24.

5. Neely JG. Complications of temporal bone infections. In: Cummings CW, Fredrickson J, Harker LA, Krause CJ, Shüller DE, ed. Otolaryngology-Head and Neck Surgery. 2nd ed. St Louis: Mosby Year Book, 1993. p.2840-2864.

6. Amadasun JEO Bacteriology of inadequately treated active chronic otitis media in paediatric age group. The Journal of Laryngology and Otology. 1991;105: 341-342.

7. Indudharan R, Haq JA, Aiyar S. Antibiotics in chronic suppurative otitis media: a bacteriologic study. Ann Otol Rhinol Laryngol 1999; 108: 440-445.

8. Ozbakkaloglu B, Surucuoglu S, Unlu H, Kurutepe S, Ozkutuk N,Degerli K. Aerobik bacteria isolated from external auditory canal in chronic suppurative otitis media cases and their in-vitro susceptibility to antimicrobials. Journal of ANKEM 1998; 12: 457-462.

9. Gorur K, Ozcan C, Unal M, Ozturk C, Delialioglu N. Bacteria isolated in chronic suppurative otitis media and antibiotic suscebility. Mersin University School of Medicine Journal 2000; 1: 48-51.

10. Gul C, Kurnaz A, Turhan V, Oncul O, Pahsa A. Microorganisms isolated from middle ear cultures and their antibacterial susceptibility in patients with chronic suppurative otitis media. The Turkish Journal of Ear Nose and Throat 2006; 16: 164-168.

11. Sharma V, Kaur G. Microbiology and Antimicrobial Susceptibility Pattern of Cases of Chronic Suppurative Otitis Media in a Tertiary Care Teaching Hospital Int. J Bioassays 2014; 3: 3033-3035.

12. Kumar KGR, Navya S, Basavarajappa KG. A Study of Bacterial Profile and Antibiotic Susceptibility Pattern of Chronic Suppurative Otitis Media among Patients attending a Tertiary Care Centre, Davangere KG Sch. J App Med Sci 2014; 2: 1606-1612.

13. Lasisi OA, Nwaorgu OG. Behavioural pattern of malignant otitis external: 10-year review in Ibadan. Afr J Med Med Sci 2001; 30: 221-223.

14. Rubin Grandis J, Branstetter BF 4th, Yu VL. The changing face of malignant (necrotising) external otitis: clinical, radiological, and anatomic correlations. Lancet Infect Dis 2004; 4: 34-39.

15. Sundstrom J, Jacobson K, Munck-Wikland E, Ringertz S. Pseudomonas aeruginosa in otitis externa. A particular variety of the bacteria? Arch Otolaryngol Head Neck Surg 1996; 122: 833-836.

16. Sanlı A, Ozturk R, Paksoy M. Determıne The Spectrum of Mciroorganisms Encountered in Outpatients with ActiveStage Chronic Supurative Otitis Media. J Kartal TR 2001; 12: 11-14.

17. Malkappa KS, Kondapaneni S, Surpam RB, Chakraverti TK. Study of Aerobic Bacterial Isolates and Their Antibiotic Susceptibility Pattern In Chronic Suppurative Otit Media Indian Journal of Otology 2012; 18: 136-113.

\section{How to cite?}

Catakoglu AH, R Guckan, Kilinc C, Erdogan MM, Alada DM, Yanik K. Antibiotic Susceptibilities of Bacteria Isolated from Chronic Suppurative Otitis Media. J Immunol Clin Microbiol 2016; 1(2). DOI: dx.doi.org/10.5455/jicm.4.20160513

Submit your next manuscript to the JICM and take full advantage of;

- Convenient online submission,

- Thorough peer review, Fast Response,

- No space constraints or color figure charges,

- Immediate publication on acceptance,

- Inclusion in Scopemed and High quality indexes,

- Research which is freely available for redistribution of the worldwide literature

To submit your manuscript, click on http://www.jiacm.com

Published by The QMEL.org International Medical Education Library

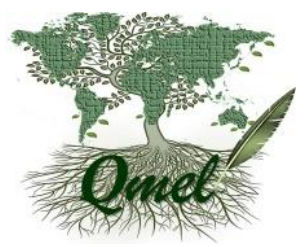

